\title{
Erratum to: Reducing the Floor Effect in the SF-6D: A Feasibility Study
}

\author{
Lara N. Ferreira ${ }^{1,3}$ • Pedro L. Ferreira ${ }^{2,3}$. \\ Luis N. Pereira ${ }^{1,4}$. Donna Rowen ${ }^{5}$
}

Published online: 13 November 2015

(C) Springer Science+Business Media Dordrecht and The International Society for Quality-of-Life Studies

(ISQOLS) 2015

\section{Erratum to: Applied Research Quality Life (2012) 7:193-208 DOI 10.1007/s11482-011-9149-3}

The article has been funded by FEDER through the COMPETE Programme and by national funds through the Foundation for Science and Technology (Fundação para a Ciência e Tecnologia) project PTDC/SAU-EPI/115151/2009. This disclaimer should have been included at the time of publication.

The online version of the original article can be found at http://dx.doi.org/10.1007/s11482-011-9149-3.

Lara N. Ferreira

Lnferrei@ualg.pt

1 School of Management, Hospitality and Tourism, University of the Algarve, Campus da Penha, 8005-139 Faro, Portugal

2 Faculty of Economics, University of Coimbra, Av. Dias da Silva, 165, 3004-512 Coimbra, Portugal

3 Centre for Health Studies \& Research, University of Coimbra, Coimbra, Portugal

4 Research Centre for Spatial and Organizational Dynamics, University of the Algarve, Faro, Portugal

5 School of Health and Related Research, University of Sheffield, Regent Court, 30 Regent Street, Sheffield S1 4DA, UK 